\title{
Antimicrobial use and resistance in Escherichia coli from healthy food- producing animals in Guadeloupe
}

Gaëlle Gruel', Arantxa Sellin¹, Hélène Riveiro1, Matthieu Pot', Sébastien Breurec ${ }^{1,2,3}$, Stéphanie Guyomard-Rabenirina' , Antoine Talarmin ${ }^{1}$ and Séverine Ferdinand ${ }^{1 *}$ (D)

\begin{abstract}
Background: Selection pressure exerted by use of antibiotics in both human and veterinary medicine is responsible for increasing antimicrobial resistance (AMR). The objectives of this study were to better understand antimicrobial use in pigs, beef cattle, and poultry on farms on Guadeloupe, French West Indies, and to acquire data on AMR in Escherichia coli in these food-producing animals. A cross-sectional survey was conducted at 45 farms on Guadeloupe, and practical use of antimicrobials was documented in declarative interviews between March and July 2018. A total of 216 fecal samples were collected between January 2018 and May 2019, comprising 124 from pigs, 75 from beef cattle, and 17 from poultry litter. E. coli isolates were obtained for further testing by isolation and

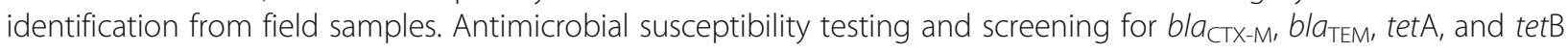
resistance genes by polymerase chain reaction on extracted genomic DNA were performed.

Results: The study showed rational use of antimicrobials, consisting of occasional use for curative treatment by veterinary prescription. Tetracycline was the most commonly used antimicrobial, but its use was not correlated to $E$. coli resistance. Extended-spectrum $\beta$-lactamase (ESBL) E. coli isolates were detected in $7.3 \%$ of pigs, $14.7 \%$ of beef cattle, and $35.3 \%$ of poultry. bla $a_{\mathrm{CTX}-\mathrm{M}-1}$ was the predominant gene found in ESBL-E. coli isolates (68.8\%), followed by bla
\end{abstract}

Conclusion: Despite rational use of antimicrobials, the rate of ESBL-E. coli in food-producing animals in Guadeloupe, although moderate, is a concern. Further studies are in progress to better define the genetic background of the ESBL-E. coli isolates.

\section{Background}

Currently, antimicrobial resistance (AMR) is one of the most urgent public health problems in the world [1]. It has dramatically increased morbidity and mortality in both humans and animals, with serious repercussions for future treatment of infections in humans and for animal health and productivity [2].

\footnotetext{
* Correspondence: sferdinand@pasteur-guadeloupe.fr

'Laboratory of Microbial Ecosystems Interactions, Transmission Reservoir and Pathogens Diversity Unit, Institut Pasteur of Guadeloupe, Morne Joliviere B.P. 484, 97183 Les Abymes Cedex, Guadeloupe, France

Full list of author information is available at the end of the article
}

Administration of antimicrobials to animals is considered to be a major contributor to the emergence of AMR worldwide [3], and several high-income countries report extensive use of antimicrobials and AMR in animals [4]. To reduce the use of antibiotics in animals, the risk factors for infectious diseases, such as the genetic background of breeds and the management of farms, must be addressed [5].

Bacterial strain diversity has played a key role in the global emergence of AMR, and selection pressure by antibiotics imbalances diversity in favor of pathogens and greater resistance [6]. The emergence of extended-

(C) The Author(s). 2021 Open Access This article is licensed under a Creative Commons Attribution 4.0 International License, which permits use, sharing, adaptation, distribution and reproduction in any medium or format, as long as you give appropriate credit to the original author(s) and the source, provide a link to the Creative Commons licence, and indicate if changes were made. The images or other third party material in this article are included in the article's Creative Commons licence, unless indicated otherwise in a credit line to the material. If material is not included in the article's Creative Commons licence and your intended use is not permitted by statutory regulation or exceeds the permitted use, you will need to obtain permission directly from the copyright holder. To view a copy of this licence, visit http://creativecommons.org/licenses/by/4.0/ The Creative Commons Public Domain Dedication waiver (http://creativecommons.org/publicdomain/zero/1.0/) applies to the data made available in this article, unless otherwise stated in a credit line to the data. 
spectrum $\beta$-lactamase (ESBL)-producing Enterobacteriaceae, which hydrolyze key antimicrobials, such as the expanded-spectrum cephalosporins cefotaxime, ceftriaxone, ceftazidime, and cefepime, is due mainly to the selective pressure of antibiotics used in both human and veterinary medicine [7]. In 2014, the antimicrobial consumption was higher in animals (152 mg of active substance per $\mathrm{kg}$ of estimated biomass) than in humans $(124 \mathrm{mg} / \mathrm{kg})$ in Europe. Consumption of 3rd- and 4thgeneration cephalosporins was associated with resistance in E. coli in humans. Tetracyclines and polymyxins resistance in $E$. coli from animals was associated with corresponding antimicrobial consumption in animals [8]. The resistance is mediated mainly by acquired ESBL genes located on mobile genetic elements and is frequently associated with resistance genes against several families of antimicrobial agents [9].

Guadeloupe, a French overseas department in the Caribbean, has been classified as a very high-resource country [10]. Less than one third of the surface of this small island is devoted to agriculture, and the livestock in 2018 comprised 14,500 pigs, 44,900 cattle, and 507,000 laying hens and broilers [11]. The latest of the few studies on AMR on Guadeloupe showed a low prevalence of ESBL-producing Enterobacteriaceae in human community-acquired urinary tract infections [12] and in wastewater treatment plants [13]. As there is close contact between humans and domestic animals, the animals may be reservoirs of resistance genes; however, the only data on antibiotic resistance in local domestic animals is a study on horses, which showed the emergence of various ESBL-producing $E$. coli clones, some of which persisted for more than a month after antibiotic treatment [14].

The main objective of this work was to obtain information on antimicrobial use on farms on Guadeloupe and on AMR levels in the zoonotic indicator bacteria $E$. coli in pigs, beef cattle, and poultry.

\section{Results}

In our survey of use of medication containing antibiotics in pigs, beef cattle, and poultry on Guadeloupe, 64.4\% $(29 / 45)$ of all farmers reported their use during the last year (Table 1). Beef cattle were individually treated, whereas collective treatments to the entire flock were administrated in pig and poultry farms. Antimicrobials were usually administered as curative treatment $(20 / 29$, $69.0 \%)$ and under veterinary prescription $(22 / 29,75.9 \%)$. The main causes for which antimicrobials were given were respiratory diseases in pigs $(5 / 11,45.5 \%)$, skin diseases in cattle $(5 / 12,41.7 \%)$, and respiratory and digestive diseases in poultry $(4 / 6,66.7 \%)$ (Table 1$)$.

The most commonly used active substance was tetracycline $(20 / 29,69.0 \%) ; \beta$-lactams and streptomycin were administered by $27.6 \%(8 / 29)$ and $24.1 \%$ (7/29) of farmers, respectively. Among farmers who administered antibiotics, the proportion of tetracycline use was significantly higher in beef cattle (100.0\%) than in pigs (54.5\%) and poultry $(33.3 \%)$. $\beta$-lactams were administered mainly by pig farmers $(54.5 \%)$, and most of the poultry producers used only trimethoprim-sulfamethoxazole (83.3\%, $P<0.001)$. Antimicrobials were used significantly less frequently in poultry $(40.0 \%)$ than in pigs (78.6\%) or beef cattle $(75.0 \%)(P=0.046)$. The median annual cost of veterinary treatment (drugs and veterinary fees) per $100 \mathrm{~kg}$ was estimated to be $7.2 €$ for pigs, $6.5 €$ for adults beef cattle, and $1.7 €$ for poultry.

A total of 216 fecal samples were collected from foodproducing animals on 28 farms and in the slaughterhouse (34 additional farms). Samples were collected from 75 adult beef cattle for meat production (51 on farms and 24 at the slaughterhouse), 124 pigs included piglets, weaned, finishers, sows and breeding males (90 on farms and 34 at the slaughterhouse), and 17 hen houses representing 53,000 poultry. The prevalence of ESBL-E. coli was higher on poultry farms (4/9, 44.4\%) than on beef cattle farms $(4 / 32,12.5 \%)$ or pig farms (3/ $21,14.3 \%)$; however, the poultry samples were from litter, representing more than one bird (Table 2).

On the basis of the observed frequencies of AMR phenotypes, corresponding to ESBL-E. coli isolated on ceftriaxone selective plates and on non-selective plates for non-ESBL-E. coli, the highest levels of resistance were against ampicillin, cefotaxime, streptomycin, tetracycline, and trimethoprim-sulfamethoxazole. Significant differences in the frequencies of resistant $E$. coli isolates were found among the three production systems (Tables 1 and 3).

We compared the rates of resistance to tetracycline, ampicillin, streptomycin, and trimethoprim-sulfamethoxazole according to the antibiotic or class of antibiotics reported in the survey, according to animal species. The number of farms in the ATB use survey is smaller than the number of farms investigated for fecal sampling. As mentioned above and shown in Table 1, although only one third of poultry farmers who used antibiotics used tetracycline as collective treatment, a high prevalence of tetracycline-resistant E. coli were found in poultry (Table 3). Use of $\beta$-lactams also did not correspond to the level of resistance to $\beta$-lactams in poultry $(17 / 23$, $73.9 \%)$, which did not receive these drugs. The proportion of tetracycline-, ampicillin-, cefotaxime-, streptomycin-, and trimethoprim-sulfamethoxazole-resistant ESBL-E. coli was similar to non-ESBL-E. coli from poultry (Table 3). ESBL-E. coli frequency was not associated to the rate of tetracycline and streptomycin resistance occurrence despite the use of these antimicrobials by half of the pig farmers. These resistances occurred 
Table 1 Use of antimicrobials in poultry, pig, and beef cattle production systems on Guadeloupe

\begin{tabular}{|c|c|c|c|c|c|c|c|c|c|}
\hline \multirow{3}{*}{ Herd size } & \multicolumn{9}{|l|}{ Farms } \\
\hline & \multirow{2}{*}{\multicolumn{2}{|c|}{$\begin{array}{l}\text { Poultry } \\
(n=15)\end{array}$}} & \multirow{2}{*}{\multicolumn{2}{|c|}{$\begin{array}{l}\text { Pig } \\
(n=14)\end{array}$}} & \multirow{2}{*}{\multicolumn{2}{|c|}{$\begin{array}{l}\text { Beef cattle } \\
(n=16)\end{array}$}} & \multirow{2}{*}{\multicolumn{2}{|c|}{$\begin{array}{l}\text { Total } \\
(n=45)\end{array}$}} & \multirow[t]{2}{*}{$P$} \\
\hline & & & & & & & & & \\
\hline mean $\pm s d$ & 12,301 & $(18,983.0)$ & 611 & $(799.0)$ & 106 & $(197.0)$ & 4327.8 & $(12,141.0)$ & \\
\hline median (iqr) & 1500 & $(19,340.0)$ & 445 & $(603.0)$ & 36 & $(50.0)$ & 400.0 & (948.0) & $<0.001$ \\
\hline \multicolumn{10}{|l|}{ Use of food supplements ${ }^{a} n,(\%)$} \\
\hline Never & 1 & $(6.7)$ & 5 & $(35.7)$ & 6 & $(35.7)$ & 12 & $(26.7)$ & \\
\hline Occasionally & 5 & (33.3) & 6 & (42.9) & 2 & $(12.5)$ & 13 & $(28.9)$ & NS \\
\hline Systematically & 9 & $(60.0)$ & 3 & (21.4) & 8 & $(50.0)$ & 20 & $(44.4)$ & \\
\hline \multicolumn{10}{|l|}{ Use of antimicrobial agent } \\
\hline Never & 9 & $(60.0)$ & 3 & (21.4) & 4 & $(25.0)$ & 16 & (35.6) & \\
\hline Occasionally & 4 & $(26.7)$ & 10 & (71.4) & 12 & $(75.0)$ & 26 & $(57.7)$ & 0.046 \\
\hline Systematically & 2 & (13.3) & 1 & (7.1) & 0 & $(0.0)$ & 3 & $(6.7)$ & \\
\hline \multicolumn{10}{|l|}{ Veterinarian is the drug supplier ${ }^{d}$} \\
\hline yes & 6 & $(100.0)$ & 8 & (72.7) & 8 & $(66.7)$ & 22 & (75.9) & NS \\
\hline Unknown & 0 & $(0.0)$ & 3 & $(27.3)$ & 4 & (33.3) & 7 & (24.1) & \\
\hline \multicolumn{10}{|l|}{ Nature of antimicrobial treatment } \\
\hline Preventive & 3 & $(50.0)$ & 5 & $(45.5)$ & 1 & (8.3) & 9 & $(31.0)$ & 0.027 \\
\hline Curative & 3 & $(50.0)$ & 6 & $(54.5)$ & 11 & $(91.7)$ & 20 & $(69.0)$ & \\
\hline \multicolumn{10}{|l|}{ Reasons for treatment ${ }^{b}$} \\
\hline Skin disease & 0 & $(0.0)$ & 1 & (9.1) & 4 & (33.3) & 5 & $(17.2)$ & \\
\hline Respiratory pathology & 1 & $(16.7)$ & 1 & (9.1) & 0 & $(0.0)$ & 2 & (6.9) & \\
\hline Skin disease and other & 0 & $(0.0)$ & 1 & (9.1) & 1 & (8.3) & 2 & (6.9) & \\
\hline Respiratory and digestive pathologies & 1 & $(16.7)$ & 1 & (9.1) & 0 & $(0.0)$ & 2 & $(6.9)$ & \\
\hline Respiratory, digestive pathologies and other ${ }^{r}$ & 1 & $(16.7)$ & 1 & (9.1) & 0 & $(0.0)$ & 2 & $(6.9)$ & NS \\
\hline Digestive pathology & 1 & $(16.7)$ & 0 & $(0.0)$ & 0 & $(0.0)$ & 1 & (3.4) & \\
\hline Skin disease and respiratory pathology & 0 & $(0.0)$ & 1 & (9.1) & 0 & $(0.0)$ & 1 & (3.4) & \\
\hline Skin disease, respiratory and digestive pathologies & 0 & $(0.0)$ & 1 & (9.1) & 0 & $(0.0)$ & 1 & (3.4) & \\
\hline Digestive pathology and other ${ }^{r}$ & 0 & $(0.0)$ & 0 & $(0.0)$ & 1 & $(8.3)$ & 1 & (3.4) & \\
\hline Other & 1 & $(16.7)$ & 4 & (36.3) & 5 & $(41.8)$ & 10 & $(34.5)$ & \\
\hline Unknown & 1 & $(16.7)$ & 0 & $(0.0)$ & 1 & (8.3) & 2 & (6.9) & \\
\hline \multicolumn{10}{|l|}{ Antimicrobials used } \\
\hline Tetracyclines & 1 & $(16.7)$ & 4 & (36.3) & 9 & $(75.1)$ & 14 & $(48.4)$ & 0.001 \\
\hline Trimethoprim-sulfamethoxazole & 4 & $(66.6)$ & 0 & $(0.0)$ & 0 & $(0.0)$ & 4 & (13.9) & \\
\hline$\beta$-lactams + streptomycin + tetracyclines & 0 & $(0.0)$ & 2 & $(18.2)$ & 1 & (8.3) & 3 & $(10.4)$ & \\
\hline$\beta$-lactams + streptomycin & 0 & $(0.0)$ & 2 & $(18.2)$ & 0 & $(0.0)$ & 2 & (6.9) & \\
\hline Tetracyclines + trimethoprim-sulfamethoxazole & 1 & $(16.7)$ & 0 & - & 0 & $(0.0)$ & 1 & (3.4) & \\
\hline$\beta$-lactams & 0 & $(0.0)$ & 1 & (9.1) & 0 & $(0.0)$ & 1 & (3.4) & \\
\hline$\beta$-lactams + tetracyclines & 0 & $(0.0)$ & 0 & $(0.0)$ & 1 & (8.3) & 1 & (3.4) & \\
\hline$\beta$-lactams + phenicols + colistin + macrolides & 0 & $(0.0)$ & 1 & (9.1) & 0 & $(0.0)$ & 1 & (3.4) & \\
\hline Streptomycin + tetracyclines & 0 & $(0.0)$ & 0 & $(0.0)$ & 1 & (8.3) & 1 & (3.4) & \\
\hline Streptomycin + phenicols + macrolides & 0 & $(0.0)$ & 1 & (9.1) & 0 & $(0.0)$ & 1 & (3.4) & \\
\hline
\end{tabular}


Table 1 Use of antimicrobials in poultry, pig, and beef cattle production systems on Guadeloupe (Continued)

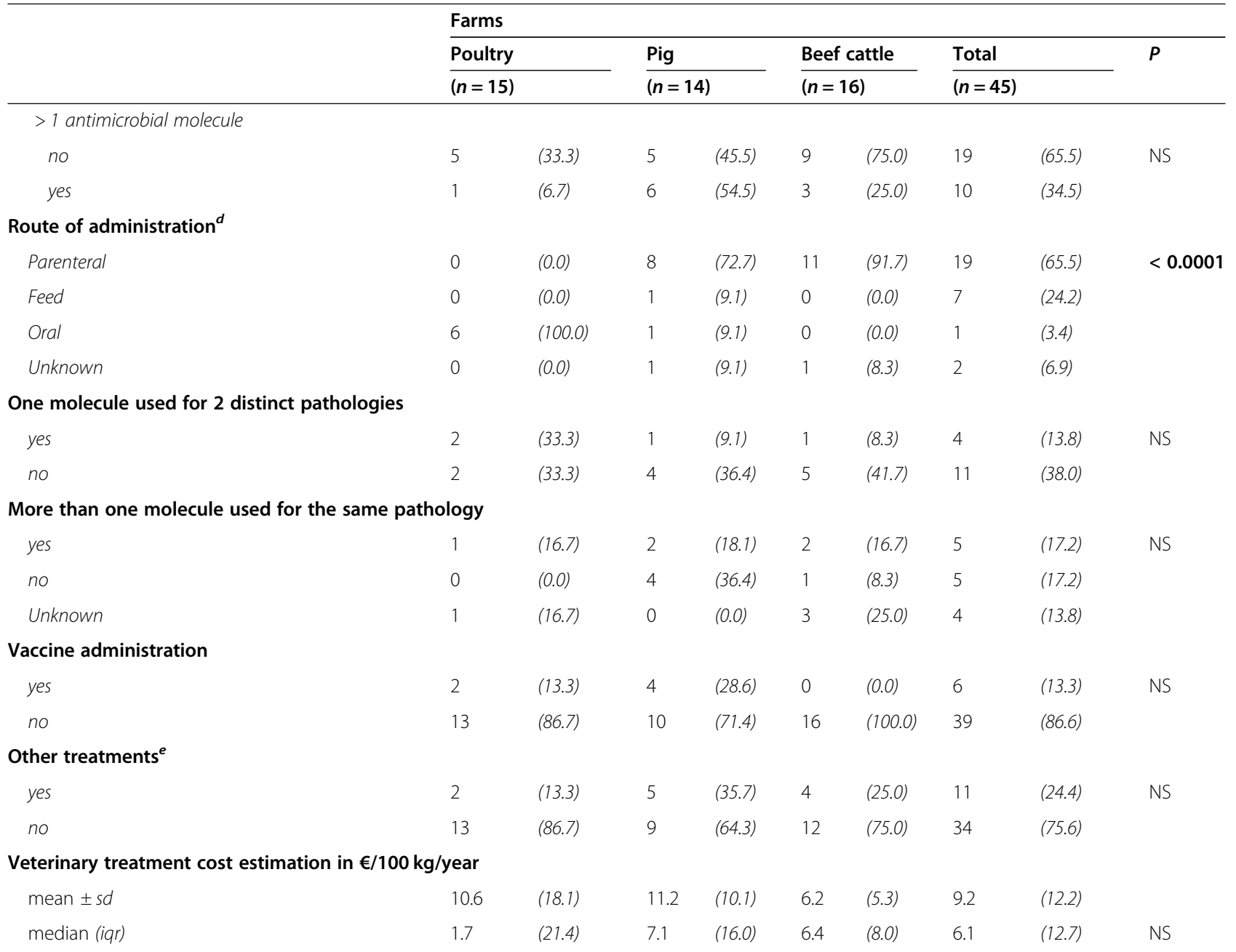

Quantitative variables are summarized as median and interquartile range (IQR) or as mean \pm standard deviation (SD). Qualitative variables are given as numbers and percentages. Intergroup differences were assessed in the Mann-Whitney test or chi-square test, as appropriate. Significant $P$ values are shown in bold NS not significant

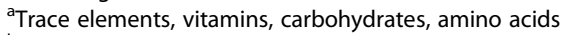

${ }^{\mathrm{b}}$ Treatments could be applied for more than one reason

Infectious diseases, reproductive diseases, ticks, leg lesions

${ }^{d}$ Percentages were calculated with the number of farmers who declared use of antimicrobials as the denominator

eAntiparasitic, antihistaminic, hepatic, medicinal plants

Table 2 Distribution of ESBL-E. coli-positive isolates

\begin{tabular}{|c|c|c|c|}
\hline \multicolumn{2}{|l|}{ Farms } & \multicolumn{2}{|l|}{ Animals } \\
\hline Total & ESBL-E. coli & Total & ESBL-E. coli \\
\hline$(n=62)$ & positive $(n=11)$ & $(n=216)$ & positive $(n=26)$ \\
\hline
\end{tabular}

$$
n,(\%)
$$

$\begin{array}{lllllll}\text { Beef cattle } & 32 & 4 & (12.5) & 75 & 11 & (14.7) \\ \text { Pig } & 21 & 3 & (14.3) & 124 & 9 & (7.3) \\ \text { Poultry } & 9 & 4 & (44.4) & 17 & 6 & \text { (35.3) }\end{array}$

ESBL, extended-spectrum $\beta$-lactamase producing isolated on selective plates independently of the detection of an ESBL. ESBL-E. coli frequency was associated to the rate of ampicillin (100.0\% of ampicillin resistance in ESBL-E. coli vs 14.4 in non-ESBL-E. coli, $P<0.001)$ and trimethoprim-sulfamethoxazole resistance occurrence $(72.7 \%$ of trimethoprim-sulfamethoxazole resistance in ESBL-E. coli vs $13.7 \%$, in non-ESBL-E. coli $P<0.001$ ), while $\beta$-lactams were used by half of the pig farmers and trimethoprimsulfamethoxazole was not declared to be used. Regardless of the antimicrobials used, ESBL-E. coli isolates from beef cattle, individually treated, were significantly associated with other resistance carriage $(P \leq 0.025)$ (Table 3$)$. Congruence was observed between the absence of quinolone use and a low frequency of nalidixic acid-resistant $E$. coli in the three animal species. 


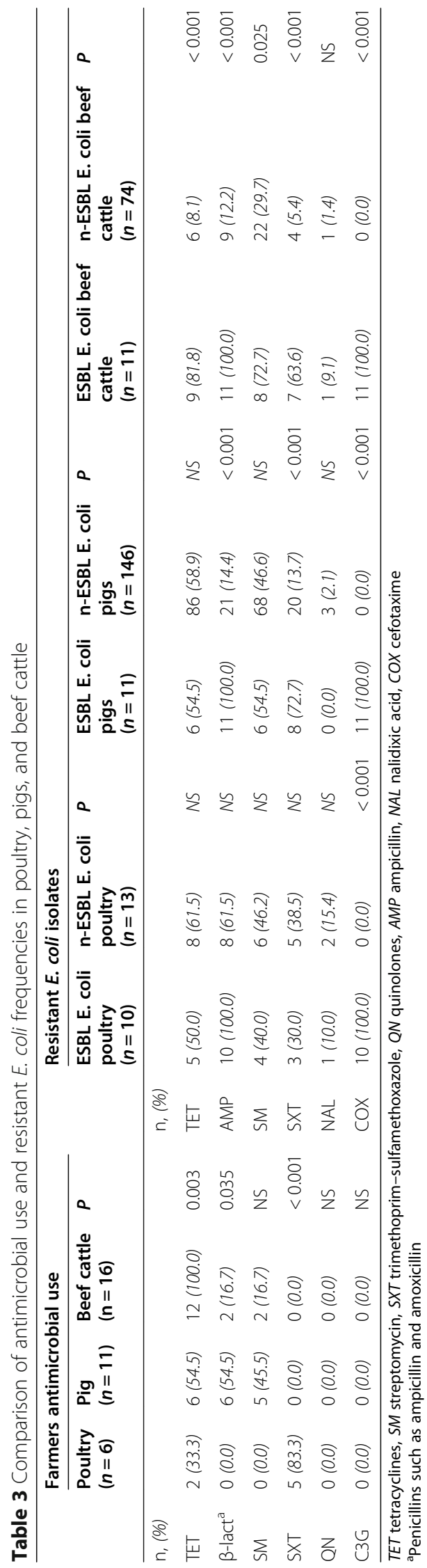


The ESBL isolates harbored predominantly the bla $_{\text {CTX-M-1 }}$ gene $(22 / 32,68.8 \%)$, followed by bla $(10 / 32,31.3 \%)$ (Table 4). The bla ${ }_{\mathrm{CTX}-\mathrm{M}-1}$ gene was combined with the bla $a_{\mathrm{TEM}-1 \mathrm{C}}$ in two pigs and with the $b l a_{\text {TEM-1B }}$ gene in one poultry isolate. The remaining ESBL-E. coli carried a bla $a_{\mathrm{CTX}-\mathrm{M}-15}$ gene, usually with combined cefotaximase and ceftazidimase activity. A comparison of phenotypic and genotypic profiles based on combined patterns analysis of AMR and antimicrobial resistance genes (ARG) is shown in Fig. 1. The bla $a_{\mathrm{CTX}-\mathrm{M}}$ genes were carried by ESBL-E. coli isolates found in the three food-producing animal systems on four farms in distinct geographic areas. The comparative analysis generated 18 distinct patterns of the 32 ESBL-E. coli (Fig. 1), with 20 (62.5\%) isolates grouped into seven clusters with similar AMR/ARG patterns (A-G) comprising two to five isolates, whereas $12(37.5 \%)$ distinct patterns were not clustered. Three clusters (A, D, G) included nine ESBL-E. coli at the same farm, whereas the other clustered ESBL-E. coli (B, C, $\mathrm{E}, \mathrm{F})$ were not specific to a production system. Twelve clustered isolates with similar AMR/ARG profiles were found in different food-producing farms (12/32, 37.5\%); e.g. one cluster of ESBL-E. coli carriers (C) consisted of two pigs and one hen house on three different farms.

\section{Discussion}

This study of antimicrobial use on small-scale pig, beef cattle, and poultry farms in Guadeloupe showed moderate ESBL-E. coli in pig and beef cattle production, probably because of rational use of antimicrobials. The island adheres to the French AMR reduction plan [15] on the use of veterinary antimicrobials, and the moderate ESBL resistance may reflect its effectiveness. The frequencies were nevertheless higher than those in French national surveillance for AMR in infected animals in 2018, in which $E$. coli isolates resistant to third- and fourthgeneration cephalosporins were detected in $2.3 \%$ of beef cattle and in $<2.0 \%$ of pigs, poultry, and turkeys [16]. The differences may be due to sampling of diseased rather than healthy animals for detection of ESBL-E. coli. The prevalence in our study is closer to that observed in Portugal, where $5.7 \%$ of fecal samples from 35 healthy pigs and $10 \%$ of those from healthy chickens were positive for ESBL-E.

Table 4 Distribution of ESBL-E. coli bla $a_{\text {CTX-M }}$ gene type

\begin{tabular}{|c|c|c|c|c|}
\hline & \multicolumn{4}{|c|}{ ESBL-E. coli isolates } \\
\hline & $\begin{array}{l}\text { Total } \\
(n=265)\end{array}$ & $\begin{array}{l}\text { bla carrier } \\
(n=32)\end{array}$ & $\begin{array}{l}b l a_{\mathrm{CTX}-\mathrm{M}-15} \\
(\mathrm{n}=10)\end{array}$ & $\begin{array}{l}b l a_{\mathrm{CTX}-\mathrm{M}-1} \\
(n=22)\end{array}$ \\
\hline \multicolumn{5}{|l|}{$n,(\%)$} \\
\hline Beef cattle & 85 & $11(12.9)$ & $6(7.1)$ & $5(5.9)$ \\
\hline Pig & 157 & $11(7.0)$ & $3(1.9)$ & $8(5.1)$ \\
\hline Poultry & 23 & $10(43.5)$ & $1(4.3)$ & $9(39.1)$ \\
\hline
\end{tabular}

bla CTX-M $\beta$-lactamase coli [17], but lower than that in Switzerland, where 15.3\% of pigs and $13.7 \%$ of bovine fecal samples were positive [18]. In European countries, the occurrence of E. coli resistance in healthy animals at slaughterhouse varied from 0 to $7.9 \%$ in fattening pigs; from 0 to $5.9 \%$ in calves under 1 year of age [19]. Country- and production-specific factors may influence the occurrence of resistance [20, $21]$. In our study, the patterns of resistance of most of the ESBL-E. coli isolates were either farm-specific or were shared by isolates from distant farms and distinct animal species. This observation suggests that ESBL-producing $E$. coli and their resistance profile spread within farms or arise independently.

None of the E. coli isolates were resistant to any of the quinolones tested (enrofloxacin, ciprofloxacin, nalidixic acid), probably reflecting the low use of these antibiotics in food-producing animals. A previous study showed a significant positive correlation between antibiotic dose and the occurrence of antibiotic-resistant bacteria in animal feces [22]. In our study, the discrepancy between the use of antimicrobials and the level of resistance is striking, as antimicrobial use was not always linked to AMR level, especially for $\beta$-lactams and tetracyclines. A potential bias might be underreported use of antimicrobials, which would explain the inverse relation, but there may be other reasons. The low level of resistance to tetracycline in beef cattle, despite the number of farms that used this drug, might be due to targeted treatment in small beef cattle production rather than the collective treatment used in larger-scale pig and poultry husbandry. Antimicrobial treatment also reflects the veterinary cost, which is lower for collective administration, e.g. to poultry. Collective treatment might therefore contribute to the emergence of resistance and should therefore be more closely controlled.

The high frequency of ESBL resistance observed in broilers (35.3\%) and to a lesser extent in pig and beef cattle farms with no use of third-generation cephalosporins is difficult to explain. We tested imported 7day old chicks 1 day after arrival from mainland France but found no resistance to these antimicrobials. It has been shown that a rapid increase in ESBL-E. coli prevalence in the first week of life must be due to factors other than latent contamination of the majority of birds at arrival [23]. Therefore, as no third-generation cephalosporins were administered in the production systems in which ESBL-E. coli resistance was detected, the observed resistance to these drugs was probably due to co-selection of several resistance genes in the same genetic determinant by other antibiotics, [24], but not specifically documented here. It has also been reported that tetracycline resistance in commensal $E$. coli is often linked to resistance to other antimicrobials, such as ampicillin 




and trimethoprim-sulfonamides [21]. A recent study on a Danish pig production farm showed clearly that commonly used antimicrobials such as tetracycline, which are not listed as critically important for human treatment, can promote resistance to critically important antimicrobials, limiting treatment possibilities [25]. A recent metagenomic study on bacterial communities showed that tetracycline resistance is often found in ESBL isolates and transmitted with ESBLcontaining plasmids [26]. Moreover, an integrated approach to AMR found an increased prevalence of integrons containing resistance genes in tetracyclineresistant isolates [27]. The wide use of tetracyclines in Guadeloupe may explain some of the disproportion between the prevalence of resistance and the use of third-generation cephalosporins. These results reinforce the importance of animal food-producing systems as a reservoir of mobile genetic elements carrying multiple resistance determinants.

Further studies are warranted to better define the genetic background of ESBL-E. coli isolates and the context of AMR on Guadeloupe, especially in food- 
producing animals that are not exposed to thirdgeneration cephalosporins.

\section{Conclusion}

Our study provides the first baseline information on levels of antimicrobial use, on the dynamics of phenotypic and genotypic resistance to tetracyclines, and on ESBL-E. coli in small-scale pig, beef cattle, and poultry production on Guadeloupe. Despite rational use of antimicrobials, E. coli resistant to third-generation cephalosporins were found on the farms. Mechanisms other than selective pressure of these antimicrobials in the emergence of AMR remain to be elucidated.

\section{Methods}

\section{Survey design}

A prospective survey on the use of antimicrobial agents in veterinary medicine and food animal production was conducted between March and July 2018 on 14 pig, 16 beef cattle, and 15 poultry production farms. The farms were selected randomly in 16 of the 32 townships of the island to ensure representative production, covering small- to large-scale cooperative or independent production. All the pig facilities were farrow-to-finishing farms, with 30-3120 head per farm, for a total of 8549 pigs, representing 59.0\% of pig production on Guadeloupe. Beef cattle breeding was investigated on 13 small-scale grassland farms ( $\leq 90$ head) and three large-scale farms, for a total of 1691 head (mean age of $4.1 \pm 2.4$ years), representing $4.3 \%$ of local meat production. The poultry breeder farms had 400-64,000 birds, for a total of 184, 510 , representing $36.4 \%$ of local production [11].

Antimicrobial use was documented in declarative faceto-face interviews with farmers by an agronomist using a questionnaire specific for the study. Each participant provided information on farm characteristics (size, number of head) and routines for antimicrobial use, including frequency, reasons for treatment, name of the antibiotic drug used, route of administration, and estimated annual cost of treatment, including laboratory analyses, veterinary services, and drug purchase.

\section{Sampling and collection}

Between January 2018 and May 2019, 11 pig farms, eight beef cattle farms, nine poultry farms, and the only slaughterhouse for beef cattle and pigs on Guadeloupe, representing respectively 24 and 10 farms, were screened for E. coli. As most small herds of beef cattle were raised free in fields, sampling was more difficult than that of pigs or poultry confined in blocks and is therefore less representative of the total production (4.3\%) [11]. During the study, 216 fecal samples $(30 \mathrm{~g})$ were collected randomly just after excretion (124 from pigs of which 34 were slaughterhouse pigs and 75 from beef cattle of which 24 were slaughterhouse beef cattle). Fecal material from 17 hen houses was sampled by walking on litter approximately $100 \mathrm{~m}$ around a flock in boot socks (Sterisocks Tryptone SodiBox, Nevez, France). All samples were stored and transported in sterile cups or bags on ice to the Institut Pasteur laboratory within $4 \mathrm{~h}$. Samples were stored at $4{ }^{\circ} \mathrm{C}$ and processed within $8 \mathrm{~h}$ of sampling.

\section{Bacterial isolation and identification}

A $10-\mu \mathrm{L}$ loop of each fecal sample was mixed in Luria Bertani broth BD Difco ${ }^{\mathrm{ma}}$ (Humeau, La Chapelle-surErdre, France) supplemented or not with $4 \mathrm{mg} / \mathrm{L}$ of ceftriaxone and incubated at $37^{\circ} \mathrm{C}$ for $24 \mathrm{~h}$. Selective enrichment with $4 \mathrm{mg} / \mathrm{L}$ of ceftriaxone were streaked on chromogenic coliform agar plates (CHROMagar ${ }^{\mathrm{rm}}$, Paris, France) supplemented with $4 \mathrm{mg} / \mathrm{L}$ of ceftriaxone. Nonselective enrichments without $4 \mathrm{mg} / \mathrm{L}$ of ceftriaxone were streaked on chromogenic coliform agar plates without $4 \mathrm{mg} / \mathrm{L}$ of ceftriaxone. All plates were incubated at $37^{\circ} \mathrm{C}$ for $24 \mathrm{~h}$. One susceptible and three resistant metallic blue colonies were randomly picked up from nonselective and selective chromogenic coliform agar, respectively and identified by matrix-assisted laser desorption and ionization time-of-flight mass spectrometry on an Axima performance spectrometer (Shimadzu Corp, Osaka, Japan).

\section{Antimicrobial susceptibility analysis}

The susceptibility of all E. coli isolates to 17 antimicrobials in six distinct classes was assessed in the standard disk diffusion method on Mueller-Hinton agar, as recommended [28]. Strains were tested against ampicillin $(10 \mu \mathrm{g})$, amoxicillin-clavulanic acid $(20 \mu \mathrm{g}-10 \mu \mathrm{g})$, temocillin $(30 \mu \mathrm{g})$, cefotaxime $(5 \mu \mathrm{g})$, ceftazidime $(10 \mu \mathrm{g})$, cefoxitin $(30 \mu \mathrm{g})$, ertapenem $(10 \mu \mathrm{g})$, gentamicin $(10 \mu \mathrm{g})$, amikacin $(30 \mu \mathrm{g})$, streptomycin $(10 \mu \mathrm{g})$, enrofloxacin $(5 \mu \mathrm{g})$, nalidixic acid $(30 \mu \mathrm{g})$, ciprofloxacin $(5 \mu \mathrm{g})$, tetracycline (30 IU), tigecycline $(15 \mu \mathrm{g})$, trimethoprim-sulfamethoxazole $(1.25 \mu \mathrm{g}-23.75 \mu \mathrm{g})$, and fosfomycin $(200 \mu \mathrm{g})$. ESBL producers were confirmed in the combined disk diffusion test with cefotaxime and ceftazidime with or without clavulanic acid. Growth inhibition diameters were measured with the Adagio ${ }^{\mathrm{Tx}}$ automated system (Bio-Rad, Marnes-La-Coquette, France). E. coli strains were classified as susceptible, intermediate, or resistant according to the epidemiological thresholds [28] and intermediate isolates were classified as resistant for further analysis. E. coli ATCC 25922 was used as a quality control. E. coli with a similar AMR profile and isolated from the same sample were considered duplicates of the same clone and were counted only once. 


\section{Resistance gene screening}

For molecular characterization of ARG, genomic bacterial DNA was extracted from one colony with the InstaGene $^{\mathrm{rm}}$ Matrix kit (Biorad, California, USA), according to the manufacturer's instructions. ESBL and tetracycline resistance coding genes were screened by PCR in all $E$. coli tetracycline-resistant isolates. bla $a_{\text {СтХ-M multiplex }}$ PCR including phylogenetic groups 1,2 , and 9 was performed [29]. bla $a_{\text {TEM }}$ gene was screened by simplex PCR [30]. Amplified PCR products were sequenced (Eurofins, Ivry-sur-Seine, France) and compared with known resistance gene sequences in the GenBank database by multiple-sequence alignment with the Basic Local Alignment Search Tool program for further characterization. Tetracycline-resistant isolates were screened for the presence of tet $\mathrm{A}$ and tet $\mathrm{B}$ genes with specific tet $\mathrm{A}$ primers designed for this study (tetA-F 5 ' -TAGAAGCC GCATAGATCGCC-3' and tetA-R 5'-GCTTCATGAG CGCCTGTTTC-3') and published specific tet $\mathrm{B}$ primers [31]. The duplex PCR amplification conditions for tet $\mathrm{A}$ and tet $\mathrm{B}$ were optimized as follow: $5 \mathrm{~min}$ at $95^{\circ} \mathrm{C}$, followed by 35 cycles at $95^{\circ} \mathrm{C}$ for $30 \mathrm{~s}$, at $62^{\circ} \mathrm{C}$ for $30 \mathrm{~s}$, and at $72{ }^{\circ} \mathrm{C}$ for $30 \mathrm{~s}$, followed by a final extension at $72^{\circ} \mathrm{C}$ for $7 \mathrm{~min}$. The amplicons were detected by gel electrophoresis. For quality control, a subsample of $10 \%$ was genotyped twice.

\section{Combined numerical analysis}

The combined numerical analysis was performed on ESBL-producing E. coli patterns with BioNumerics ${ }^{\circ}$ v6.6 software (Applied Maths NV). Each file with experimental data from AMR and ARG screening was merged as a composite data set in the BioNumerics ${ }^{\circ}$ database, with the similarity coefficient option taken from each experiment. The matrices from the individual experiments were averaged according to the same defined weight, and an individual similarity matrix was calculated in such a way that all characters had an equal influence on similarity. A dendrogram was drawn by using the unweighted pair group method with arithmetic averages with a tolerance of $1 \%$ to show the similarity of combined AMR and ARG patterns of the bacterial isolates.

\section{Statistical analysis}

Results are presented as means \pm standard deviation, medians with the interquartile ranges for quantitative variables, and numbers and percentages for qualitative variables. Intergroup differences among farms classified according to food-producing animal category were assessed with the Kruskal-Wallis or chi-square test, as appropriate. The level of significance was defined as $P<0.05$. Analyses were conducted with STATA ${ }^{\circ} 11.2$.

\section{Abbreviations}

AMR: Antimicrobial resistance; ESBL: Extended-spectrum $\beta$-lactamase; TET: Tetracycline; SM: Streptomycin; SXT: Trimethoprim-sulfamethoxazole; QNR: Quinolones; AMP: Ampicillin; NAL: Nalidixic acid; ARG: Antimicrobial resistance genes; PCR: Polymerase chain reaction; iqr: interquartile range; sd: standard deviation

\section{Acknowledgments \\ The authors would like to thank the farmers who participated in the study for their help in sampling during the fieldwork and the slaughterhouse director for facilitating access. We thank Jean-Christophe Bambou, Jean-Luc Gourdine (INRAe, Guadeloupe), and Olivier Roy (Chairman of the association of liberal veterinarians, AVPLG, Guadeloupe) for their useful help in question- naire designing. We also thank Professor G. Arlet (Tenon Hospital, Paris, France) who provided positive E. coli control strains for resistance screening by PCR.}

\section{Authors' contributions}

GG, AS, HR, and MP performed sampling and bacteriological analysis. SB and $S G$ revised and edited the manuscript. AT supervised the research and substantially revised the draft. SF designed the study, supervised research, performed the statistical analyses and drafted and edited the manuscript. All the authors have read and approved the manuscript, and agreed to be accountable for their own contributions in ensuring that questions related to the accuracy or integrity of any part of the work are appropriately investigated and resolved.

\section{Funding}

This work was supported by the Programme Opérationnel FEDERGuadeloupe-Conseil Régional 2014-2020 (Grant number 2015-FED-192). GG is funded by a PhD fellowship from La Région Guadeloupe. The funders were not involved in the design of the study and collection, analysis, and interpretation of data and in writing the manuscript.

Availability of data and materials

The datasets analyzed during the current study are available from the corresponding author on reasonable request.

\section{Declarations}

\section{Ethics approval and consent to participate}

As fecal samples were taken from animals at the slaughterhouse and in the field after excretion, "use of live animals for scientific purposes" (within the meaning of the Rural Code, Art R214-87 and following) was not relevant; no invasive procedure was conducted on live animals. Furthermore, the project was considered to be outside the scope of the regulations on animal experimentation by the chairman of the Ethics Committee on animal experimentation of the Antilles and Guyane (registered with the French Ministry of Higher Education, Research and Innovation No. 69). Thus, according to French national law for the protection of animals (No. 2013118), which reproduces European directive 2010/63/UE on the protection of animals used for experimental and other scientific purposes, no ethics committee approval was deemed necessary according to Article 7.1 on recommendations for animal welfare and Article 7.8 on use of animals in research and education of the World Organization for Animal Health Terrestrial Animal Health Code, used in France. The entity responsible for the animals was the slaughterhouse, and authorization for sample collection was obtained from the director of the slaughterhouse. Sampling of pig, beef cattle, and chicken feces was authorized verbally by the owners, who are responsible for the animals.

Consent for publication

Not applicable.

\section{Competing interests}

The authors declare that they have no competing interests.

\section{Author details}

${ }^{1}$ Laboratory of Microbial Ecosystems Interactions, Transmission Reservoir and Pathogens Diversity Unit, Institut Pasteur of Guadeloupe, Morne Joliviere B.P. 484, 97183 Les Abymes Cedex, Guadeloupe, France. ${ }^{2}$ Faculté de 
Médecine Hyacinthe Bastaraud, Université des Antilles, Pointe-à-Pitre, Guadeloupe, France. ${ }^{3}$ Centre d'Investigation Clinique, INSERM CIC 1424 Pointe-à-Pitre, Guadeloupe, France.

Received: 10 June 2020 Accepted: 19 February 2021

Published online: 08 March 2021

\section{References}

1. O'Neill J. Antimicrobial resistance : tackling a crisis for the health and wealth of nations. Rev Antimicrob Resist. 2014. https://amr-review.org. Accessed 18 Aug 2018.

2. Eurosurveillance editorial team. WHO member states adopt global action plan on antimicrobial resistance. Euro Surveill. 2015;20. https://pubmed.ncbi. nlm.nih.gov/26062562/

3. Prestinaci F, Pezzotti P, Pantosti A. Antimicrobial resistance: a global multifaceted phenomenon. Pathog Glob Health. 2015;109:309-18. https:// doi.org/10.1179/2047773215Y.0000000030.

4. EFSA (European Food Safety Authority) and ECDC (European Centre for Disease Prevention and Control). The European Union summary report on antimicrobial resistance in zoonotic and indicator bacteria from humans, animals and food in 2017. EFSA J. 2019. https://doi.org/10.2 903/j.efsa.2019.5598.

5. Bokma J, Boone R, Deprez P, Pardon B. Risk factors for antimicrobial use in veal calves and the association with mortality. J Dairy Sci. 2019;102:607-18 https://doi.org/10.3168/jds.2018-15211

6. Borrell S, Trauner A. Strain diversity and the evolution of antibiotic resistance. Adv Exp Med Biol. 2017;1019:263-79. https://doi.org/10.1007/ 978-3-319-64371-7 14

7. Paterson DL, Bonomo RA. Extended-Spectrum $\beta$-lactamases: a clinical update. Clin Microbiol Rev. 2005;18:657-86. https://doi.org/10.1128/CMR.1 8.4.657-686.2005.

8. ECDC (European Centre for Disease Prevention and Control), EFSA (European Food Safety Authority), and EMA (European Medicines Agency), 2017. ECDC/EFSA/EMA second joint report on the integrated analysis of the consumption of antimicrobial agents and occurrence of antimicrobial resistance in bacteria from humans and food-producing animals - Joint Interagency Antimicrobial Consumption and Resistance Analysis (JIACRA) Report. EFSA J. 2017;15(7):4872, 135 pp. https://doi.org/10.2903/j.efsa.2017.4 872.

9. Peirano G, Pitout JDD. Extended-Spectrum $\beta$-lactamase-producing Enterobacteriaceae: update on molecular epidemiology and treatment options. Drugs. 2019;79:1529-41. https://doi.org/10.1007/s40265-019-011 80-3.

10. Sub-national HDI. Area Database. 2018. https://globaldatalab.org. Accessed 20 May 2020

11. Agreste. Memento de la statistique agricole - Guadeloupe. 2019;:32pp. http://daaf.guadeloupe.agriculture.gouv.fr/IMG/pdf/Memento_Guadeloupe_ Edition_2019_cle4928a1.pdf. Accessed 11 May 2020.

12. Guyomard-Rabenirina S, Malespine J, Ducat C, Sadikalay S, Falord M, Harrois D, et al. Temporal trends and risks factors for antimicrobial resistant Enterobacteriaceae urinary isolates from outpatients in Guadeloupe. BMC Microbiol. 2016:16:121. https://doi.org/10.1186/s12866-016-0749-9.

13. Guyomard-Rabenirina S, Dartron C, Falord M, Sadikalay S, Ducat C, Richard $V$, et al. Resistance to antimicrobial drugs in different surface waters and wastewaters of Guadeloupe. Plos One. 2017;12:e0173155. https://doi.org/1 0.1371/journal.pone.0173155.

14. Sadikalay S, Reynaud Y, Guyomard-Rabenirina S, Falord M, Ducat C, Fabre L, et al. High genetic diversity of extended-spectrum $\beta$-lactamases producing Escherichia coli in feces of horses. Vet Microbiol. 2018;219:117-22. https:// doi.org/10.1016/j.vetmic.2018.04.016.

15. Ecoantibio2. The french national plan for the reduction of the risks of antimicrobial resistance in veterinary medecine 2017-2021. 2017::18pp. https://agriculture.gouv.fr/. Accessed 10 Oct 2018.

16. ANSES. Résapath-Réseau d'épidémiosurveillance de l'antibiorésistance des bactéries pathogènes animales, bilan 2018. Lyon et Ploufragan-PlouzanéNiort, France. 2019::161pp. https/::resapath.anses.fr/. Accessed 8 Dec 2019.

17. Machado E, Coque TM, Cantón R, Sousa JC, Peixe L. Antibiotic resistance integrons and extended-spectrum $\beta$-lactamases among Enterobacteriaceae isolates recovered from chickens and swine in Portugal. J Antimicrob Chemother. 2008;62:296-302. https://doi.org/10.1093/jac/dkn179.
18. Geser N, Stephan R, Hächler H. Occurrence and characteristics of extendedspectrum $\beta$-lactamase (ESBL) producing Enterobacteriaceae in food producing animals, minced meat and raw milk. BMC Vet Res. 2012;8:21. https://doi.org/10.1186/1746-6148-8-21

19. Authority EFS, European Centre for Disease Prevention and Control. The European Union Summary Report on Antimicrobial Resistance in zoonotic and indicator bacteria from humans, animals and food in 2017/2018. EFSA J. 2020;18:e06007. https://doi.org/10.2903/j.efsa.2020.6007.

20. Österberg J, Wingstrand A, Nygaard Jensen A, Kerouanton A, Cibin V, Barco $\mathrm{L}$, et al. Antibiotic resistance in Escherichia coli from pigs in organic and conventional farming in four European countries. Plos One. 2016;11: e0157049. https://doi.org/10.1371/journal.pone.0157049.

21. Dewulf J, Catry B, Timmerman T, Opsomer G, de Kruif A, Maes D. Tetracycline-resistance in lactose-positive enteric coliforms originating from Belgian fattening pigs: degree of resistance, multiple resistance and risk factors. Prev Vet Med. 2007;78:339-51. https://doi.org/10.1016/j.prevetmed.2 006.11.001.

22. Yang $P$, Chen $Y$, Jiang $S$, Shen $P$, Lu X, Xiao Y. Association between antibiotic consumption and the rate of carbapenem-resistant gram-negative bacteria from China based on 153 tertiary hospitals data in 2014. Antimicrob Resist Infect Control. 2018;7:137. https://doi.org/10.1186/s13756018-0430-1.

23. Dierikx CM, van der Goot J, van Essen-Zandbergen A, Mevius DJ. Dynamics of cefotaxime resistant Escherichia coli in broilers in the first week of life. Vet Microbiol. 2018;222:64-8. https://doi.org/10.1016/j.vetmic.2018.07.001.

24. Pitout JD, Laupland KB. Extended-spectrum $\beta$-lactamase-producing Enterobacteriaceae: an emerging public-health concern. Lancet Infect Dis. 2008:8:159-66. https://doi.org/10.1016/\$1473-3099(08)70041-0.

25. Jensen LB, Birk T, Borck Høg B, Stehr L, Aabo S, Korsgaard H. Cross and co resistance among Danish porcine E. coli isolates. Res Vet Sci. 2018;119:247-9. https://doi.org/10.1016/j.rvsc.2018.07.002.

26. Tacão M, Moura A, Correia A, Henriques I. Co-resistance to different classes of antibiotics among ESBL-producers from aquatic systems. Water Res. 2014; 48:100-7. https://doi.org/10.1016/j.watres.2013.09.021.

27. Belaynehe KM, Shin SW, Yoo HS. Interrelationship between tetracycline resistance determinants, phylogenetic group affiliation and carriage of class 1 integrons in commensal Escherichia coli isolates from cattle farms. BMC Vet Res. 2018;14:340. https://doi.org/10.1186/s12917-018-1661-3.

28. VetCAST. Veterinary Committee on Antimicrobial Susceptibility Testing (VetCAST). Clinical breackpoints and dosing. 2019. https://www.eucast.org/a st_of_veterinary_pathogens/. Accessed 16 Mar 2019.

29. Dallenne C, da Costa A, Decré D, Favier C, Arlet G. Development of a set of multiplex PCR assays for the detection of genes encoding important $\beta$ lactamases in Enterobacteriaceae. J Antimicrob Chemother. 2010:65:490-5. https://doi.org/10.1093/jac/dkp498

30. Arlet G. Substitution of alanine for aspartate at position 179 in the SHV-6 extended-spectrum $\beta$-lactamase. FEMS Microbiol Lett. 1997;152:163-7. https://pubmed.ncbi.nlm.nih.gov/9228783/

31. Guardabassi L, Dijkshoorn L, Collard JM, Olsen JE, Dalsgaard A. Distribution and in-vitro transfer of tetracycline resistance determinants in clinical and aquatic Acinetobacter strains. J Med Microbiol. 2000;49:929-36. https://doi. org/10.1099/0022-1317-49-10-929.

\section{Publisher's Note}

Springer Nature remains neutral with regard to jurisdictional claims in published maps and institutional affiliations.

Ready to submit your research? Choose BMC and benefit from:

- fast, convenient online submission

- thorough peer review by experienced researchers in your field

- rapid publication on acceptance

- support for research data, including large and complex data types

- gold Open Access which fosters wider collaboration and increased citations

- maximum visibility for your research: over $100 \mathrm{M}$ website views per year

At BMC, research is always in progress.

Learn more biomedcentral.com/submissions 